\title{
A IMAGEM DOS REFUGIADOS KOSOVARES EM JORNAIS ITALIANOS ENTRE MARÇO E JUNHO DE 1999
}

\author{
Kamila Kowalska* \\ (Tradução do italiano por pe. Giuseppe Bortolato)
}

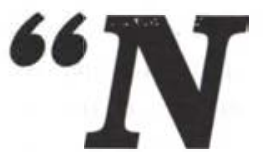

o transcorrer da última semana de março de 1999, o mundo foi invadido pelas imagens televisivas dos albaneses que fugiam do Kosovo. As cenas apresentadas comoviam os numerosos espectadores do mundo todo e os repórteres de televisão, especialmente aqueles das maiores agências, entre as quais BBC, CNN, SKY, etc., informavam a respeito das tragédias de gente obrigada a deixar as próprias casas. Eram exibidas as imagens da destruição completa de refinarias, pontes, casas, fábricas e estações de TV. Em meio a isso tudo, podiam ser vistas as multidões de jovens que se manifestavam nas praças das cidades sérvias, cantando e proclamando slogans cheios de ironia, raiva mas também de humorismo. Em seguida se voltava ainda às imagens das casas destruídas, do trem que tinha sido bombardeado e dos rostos destruídos de albaneses em fuga, que se dirigiam em fila em direção às fronteiras..." (Lukovic,2000:7).

De um ponto de vista geral, não há dúvida de que o papel dos Meios de Comunicação, na difusão das informações a respeito dos acontecimentos de países diferentes e distantes, no que tange às guerras, os fugitivos, mas também a respeito da imagem dos estrangeiros, da imigração e da variedade das culturas é muito relevante e, outrossim, indispensável. As coisas, às quais um espectador por si só jamais poderia ter acesso, por motivos de língua e cultura,bem como pelas grandes distâncias, ou simplesmente pela periculosidade da situação em casos de conflitos, tudo isso vem superado através dos Meios de Comunicação, que nos trazem diretamente em casa qualquer imagem. A pergunta fundamental que se impõe é, porém, até que ponto a imagem transmitida reflete o objeto em questão de forma neutra e quando, pelo contrário, começa a condicionar o espectador. Para que a imprensa não tenda a reproduzir uma imagem estereotipada ou prejudicial dos estrangeiros e das diversidades, no decorrer do último decênio foram assinadas, na Itália, três cartas de princípios com relação à imprensa e imigração: a Declaração do compromisso de uma informação pluralista (1993-1994), a Carta de Ercolano (1995) e as Recomendações para uma informação não racista (1996). As regras anunciadas nesses documentos convidam os jornalistas a combater os estereótipos sobre a imigração, a abster-se de julgamentos que não sejam comprovados pelos fatos, a evitar julgamentos e discriminações na linguagem e nas manchetes e a levar em conta a mudança do sentido das palavras no tempo. Os resultados obtidos pelas pesquisas, no âmbito da relação dos Meios de Comunicação italianos e os imigrantes, entre eles, as pesquisas realizadas pelo Centro de Estudos Inter-culturais da Universidade de Verona nos anos 19982002; pelo Censis a respeito do tema dos imigrantes e das minorias étnicas nos Meios de Comunicação (realizado entre maio e setembro de 2001); pela agência ANSA, e também do estudo aqui apresentado, é mais que evidente que estes princípios nem sempre foram obedecidos e plenamente respeitados (Licata, 2003:128).

$\mathrm{E}$ isto acontece pelo fato de que a relação entre imigrantes e Meios do Comunicação adquire uma característica relevante: não é uma relação equânime, recíproca e, consequentemente, assume com frequência, uma forma desequilibrada pelo "peso" maior de uma das partes, os meios de comunicação. A concorrência entre os meios de comunicação, a força de uns e a fraqueza de outros, a briga permanente pelo furo de reportagens ou 
pela notícia mais impactante, fazem com que existam sempre mais pontos de interrogação com relação à neutralidade da notícia e a influência a respeito da informação por parte de quem a transmite.

Os meios de comunicação, no que tange à imigração, detêm o poder absoluto, pois são eles mesmos os criadores da imagem dos estrangeiros que será absorvida depois pela sociedade.

Nem sempre o destinatário que recebe a informação através dos meios de comunicação está em condições de questionar se a imagem é de fato real, ou se está influenciada pela opinião política e pela formação de quem informa, da linha política dos meios de comunicação, da opinião pública corrente, ou ainda pela necessidade de evidenciar uma certa notícia para poder encobrir uma outra. Os meios de comunicação se defendem afirmando, repetidamente, que o papel deles no desempenho da infomação, da instrução e da atualização permanente, considerando a diversidade de interesses no interior da próporia sociedade, é muito complexo; portanto, para conseguir alcançar a todos sentem-se obrigados a simplificar a notícia, usando modelos já existentes e bem compreensíveis. Pode ser até verdade: precisa, porém, tomar consciência do fato que através dos modelos nem sempre se consegue traduzir a realidade.

\section{O FENÔMENO DA "MEDIATIZAÇÃO" E AS SUAS CONSEQUENCIAS NA ITÁLIA}

A questão do quarto poder, ou seja, o poder da mídia e o papel da mesma em influenciar e guiar tanto as decisões políticas, quanto a opinião pública, conhecido também como "o efeito CNN", é considerado por muitos preocupante e, mais que isso, questionável. "Este problema, sobretudo na caso da assim chamada 'mediatização' da política, emergiu depois da Segunda Guerra Mundial, junto com o desenvolvimento dos meios de comunicação e da descoberta e evolução das técnicas de persuasão cada vez mais presentes nos discursos dos políticos. A 'mediatização' da vida política, considerada como o sinal dos nossos tempos, faz com que a esfera política seja transformada e modernizada pelos meios de comunicação, os quais não representam mais, exclusivamente, os porta-vozes oficiais, mas assumem o papel de poderosos atores da política mundial, capazes de criar suas próprias idéias e formar uma nova opinião pública" (DobekOstrowska, 1999:128). Por quanto o fenômeno do "efeito CNN" possa ser marginalizado ou mesmo ignorado pelos próprios políticos, não há dúvidas que na maior parte dos conflitos acontecidos recentemente (se não em todos), a influência e a relevância da mídia em criar o clima da opinião pública foi bastante notável. Tudo isto vem causado pelo fato que, escolhendo uma notícia para transmitir, "os meios de comunicação concentram a atenção da sociedade em alguns fatos, frequentemente aqueles de maior visibilidade, como as guerras, os atentados terroristas, as revoluções e as catástrofes, ignorando os demais. Promovem assim um tipo de hierarquia dos temas "importantes" e fortemente sentidos pela sociedade, portanto, não indiferentes às decisões tomadas pelos políticos" (Dobek-Ostrowska, 1999:133). Esta realidade corresponde a uma outra teoria das ciências da comunicação, isto é, a teoria da "agenda setting" (agenda fechada), introduzida em 1963 por B. Cohen, que em uma de suas obras constatou que "os meios de comunicação sugerem não tanto o que pensar, quanto de que pensar" (Goban-Klas, 1999:267): portanto, certos acontecimentos adquirem maior relevância que outros, mesmo sendo semelhantes quando não até iguais. Assim como aconteceu no caso de tantos conflitos armados entre os quais alguns obtiveram a máxima atenção por parte da opinião pública (ex.: conflito em Kosovo ou conflito Israel-Palestina), enquanto outros, pelo contrário, como aqueles em Angola, Borundi, Sudão, Serra Leoa, Tchetchênia, etc., foram completamente esquecidos.

A questão da manipulação da informação por parte da mídia, focalizando alguns temas e relegando outros, não diz respeito somente aos denominados novos meios de comunicação, como internet ou TV via satélite, mas da mesma forma está presente naqueles tradicionais, isto é, na imprensa escrita. O motivo disso encontra justificativa no fato de que os diários raramente são lidos do começo ao fim, atentamente e com calma. Frequentemente, pelo contrário, são somente vistos superficialmente, sem pensar e, portanto, para um aprofundamento, são escolhidos poucos textos, aqueles que parecem interessantes pela manchete, pela caricatura ou mesmo aqueles que transmitem a notícia em uma ou duas frases. Este fenômeno, chamado por Umberto Eco "fruição da desatenção", usado pelas redações dos diários e semanais do mundo todo, faz com que seja lido apenas aquilo que é sugerido pelos jornalistas e do modo como é por eles interpretado. Não obstante a teoria do "efeito CNN" pareça ser adotada sobretudo pelos meios televisivos, dos quais provêm também o nome do mesmo fenômeno, também a imprensa escrita utiliza-se das "técnicas de indução" naquilo que diz respeito aos temas mais e menos relevantes.

As técnicas mais evidentes são aquelas relativas à página na qual o artigo vem publicado, levando em conta que, principalmente, são a primeira e a segunda página as que determinam a maior importância da notícia, o espaço dedicado ao texto (o número de colunas) e também a localização na página onde vem inserida a matéria. $\mathrm{O}$ artigo mais importante, isto é, o artigo que abre cada número do jornal se encontra habitualmente na primeira página, no alto, à direita, de modo tal a atrair imediatamente a atenção do leitor; aquele relativamente menos significativo, em baixo, à esquerda.

Mas existem outras técnicas, dentre as quais: a disposição das fotos, colocadas ao lado dos principais textos; a apresentação de uma questão de forma tendenciosa e exclusivamente de um único ponto de vista; a continuidade da temática no número seguinte, para fazer com que o jornal seja adquirido também no dia seguinte, bem como a do tamanho e do formato das letras nas manchetes (Ricci, s/d). A manipulação da informação por parte dos meios de comunicação, seja através do conteúdo 
ou daquilo que diz respeito às técnicas profissionais, através das quais um fenômeno, uma cultura, um povo são favorecidos em relação a um outro, é um problema muito presente na realidade dos dias atuais e um tanto quanto perigosa. De modo todo especial lá onde a influência e o papel dos meios de comunicação em criar e formar a opinião pública é maior que qualquer outra coisa: assim como, sem dúvida, acontece na Itália.

Os dados da sondagem realizada junto ao diário "La Repubblica" em novembro de 2002 , revelam que $41 \%$ das pessoas entrevistadas passam de duas a quatro horas diárias assistindo televisão, 35\% duas horas diárias, enquanto $21 \%$ ultrapassam as quatro horas (Bordignon, 2002:14). O problema do papel tão significativo dos meios de comunicação para os italianos e a sua dependência em relação aos programas televisivos e da imprensa escrita, vem sendo estudado há muito tempo por sociólogos e psicólogos, os quais ressaltam o grande risco deste fato, visto que para um alto índice da população, a informação transmitida é aceita de modo cego e com credibilidade absoluta.

\section{O CONTEXTO DA OPINIÃO PÚBLICA NA ITÁLIA NO INÍCIO DO CONFLITO NO KOSOVO}

À luz desta realidade, pareceu-me particularmente interessante desenvolver uma pesquisa sobre o tema das imagens dos kosovares, criada pela imprensa escrita italiana durante o conflito no Kosovo, ou seja no período entre 24 de março e 10 de junho 1999. Os motivos da peculiar escolha deste argumento foram vários, entre os quais o mais relevante foi aquele referente ao esteriótipo negativo ainda existente na sociedade italiana com relação aos vizinhos procedentes da Albânia. Os albaneses, portanto também os Kosovares, são vistos principalmente como o povo da imigração ilegal, que desembarca diariamente dos botes nas orlas italianas da
Pugllia, como ladrões, personagens das páginas policiais, traficantes de drogas, de seres humanos e de armas. Repentinamente, porém, de um dia para o outro, o povo albanês viu-se desempenhando o papel de bom, enquanto vítima inocente de uma guerra injusta, dos bombardeios da NATO (e portanto também da Itália). Era evidente que os meios de comunicação deveriam reagir, alterando esta imagem negativa, causada pelos preconceitos profundamente arraigados na sociedade e criados pela própria mídia. O conflito no Kosovo representava um dos poucos casos em que não era possível aplicar "a espiral do silêncio", fazendo esquecer esta guerra e ignorando as suas consequências, como tem sido feito em muitas outras ocasiões. O Kosovo estava próximo demais da Itália e o próprio conflito já havia provocado um forte impacto em todo o mundo. Em toda parte as pessoas protestavam contra esta guerra e o mesmo o faziam os italianos. Manifestavam o seu desacordo em relação aos bombardeios e ao envolvimento direto por parte do Estado italiano, através das manifestações em favor da paz pelas ruas das maiores cidades do país, como Roma, Milão, Firenze e Nápoles. Tem sido embaraçoso a todos eles saber que foi da própria Itália, da base militar de Aviano, que havia partido o primeiro avião da NATO para atingir a Sérvia e por conseguinte, dando início ao conflito. Tudo isto, juntamente com as preocupações das agências humanitárias sobre um possível afluxo maciço para a Itália dos kosovares vítimas da guerra, em virtude da ausência de um dispositivo legal em matéria de asilo e de infra-estrutura adequada para acolher os refugiados, tem criado um conjunto de fatores e de situações anômalas.

Não se pode omitir, finalmente, a voz do Vaticano, ou seja, do Papa, que durante os 77 dias de duração do conflito, sequer por um instante deixou de lançar, do coração da Itália, o apelo para o término desta tragédia humana, ou seja, do conflito no Kosovo.

Uma vez criada uma espécie de "questão italiana" no interior do conflito no Kosovo, os meios de comunicação não poderiam permanecer calados: e têm, de fato, reagido imediatamente, acompanhando o conflito com atenção do início até o fim.

\section{UMA VISÃO GERAL DOS JORNAIS ANALISADOS AO LONGO DA PESQUISA}

Na Itália, ao longo dos últimos anos, os estudos e as análises sobre a relação entre os meios de comunicação italianos e os cidadãos estrangeiros tem sido assunto cada vez mais presente nas pesquisas voltadas para o campo social, assim como continua aumentando a evidência e a importância da presença dos imigrantes em território italiano.

Também neste meu estudo procurarei examinar o fenômeno em questão, situando-o, porém, em um contexto muito particular, que conforme já assinalei anteriormente, tem influenciado muito o início, o desenvolvimento e a finalização "do problema": a visão da mídia em relação ao conflito no Kosovo e aos próprios kosovares.

A primeira parte deste trabalho se deterá na análise quantitativa, ou seja, sobre o número de textos (entre os que foram publicados em primeira página), o número de páginas e de fotos dedicadas ao tema dos kosovares em cada jornal examinado ao longo da pesquisa.

A segunda parte, porém, será dedicada à análise qualitativa do conteúdo, ou seja, a imagem dos kosovares criada pelos jornais, analisando o impacto na opinião pública, os temas, as sondagens efetuadas pelos jornais, bem como a terminologia, por exemplo, as manchetes e as palavras chaves usadas para referir-se aos fugitivos de guerra kosovares.

Para conseguir desenvolver esta pesquisa sobre a imagem dos kosovares nos meios de comunicação italianos de maneira séria e o mais representativa possível, resolvi deter-me apenas sobre os jornais, renunciando à análise dos meios televisivos, visto que muito mais complexos. Para conseguir, porém, que fosse contemplado inteiramente o panorama dos alinhamentos políticos, propiciando uma imagem complexa das opiniões e dos pontos de vista, escolhi, propositadamente, apenas cinco diários, entre os muitos existentes, a saber: $I l$ 
Manifesto, La Repubblica, La Stampa, Il Corriere della Sera e Il Tempo.

Il Manifesto, fortemente alinhado à esquerda, enquanto comunista, diferentemente dos demais jornais analisados, prioriza as notícias de caráter internacional em relação as de caráter nacional, o que ficou muito evidenciado durante o conflito em questão. Il Manifesto foi o único, entre os cinco analisados, a criticar abertamente as decisões do governo italiano, acusando-o de violar o direito internacional (Murialdi, 1998:2001). Mesmo utilizando com frequência em seus artigos uma linguagem sarcástica, irônica ou palavras com significado forte, foi sem dúvida o jornal que tratou do tema Kosovo, kosovares de maneira mais completa, dedicando o maior número de páginas e de artigos.

La Repubblica, La Stampa, Il Corriere della Sera, os mais significativos para todos os italianos e os mais importantes e de maior inflência em âmbito nacional e internacional, têm tratado do conflito no Kosovo de modo semelhante. Enquanto de tendência mais ou menos de centro, sendo - La Repubblica considerado mais de centro-esquerda, os três concentraram-se em noticiar os fatos, comentá-los e a projetar possíveis soluções para o futuro, dedicando ao conflito um número igual de textos. Os artigos neles publicados divergiam em muito daqueles do $I l$ Manifesto, mais prudentes nas palavras, menos sensacionalistas e decididamente "politicamente corretos". A temática da guerra no Kosovo, vista a partir das suas redações, às vezes vinha tratada propositadamente com o intuito de envolver os italianos e fazê-los refletir sobre as implicações que este conflito trazia e poderia trazer para a situação interna do país. Ao difundir as imagens mais "comoventes" dos kosovares e ao transformar os refugiados em personagens "lendários" sobressaía-se, entre os três, de modo particular, La Stampa, que com insistência procurava, através da narração das histórias de vida das vítimas da guerra, criar uma atmosfera "melo-dramática".

Um exemplo muito peculiar tem sido aquele do jornal $l l$ Tempo, um tradicional jornal romano, popular e conservador, de tendência centro-direita. O seu modo de dar as informações quanto ao conflito do Kosovo foi aquele que conseguiu o maior envolvimento dos leitores, através de sondagens e pesquisas sobre temáticas específicas entre os mesmos. Il Tempo tem dedicado o menor espaço ao tema da guerra no Kosovo entre os cinco jornais, centrando-se principalmente nas questões políticas antes que sobre aquelas de caráter humanitário e sobre a situação e as condições vivenciadas pelos refugiados.

\section{A ANÁLISE QUANTITATIVA: 0 CONFLITO NO KOSOVO E OS KOSOVARES EM NÚMEROS}

A análise dos artigos publicados sobre os periódicos em questão fez emergir as diferenças existentes, manifestadas principalmente na crítica ou no apoio à decisão do governo de tomar parte no conflito, já durante a primeira semana após o ínicio dos bombardeios. E assim como diversas eram as suas opiniões sobre o conflito, também variava o modo de transmitir as informações sobre a guerra: Iam do destaque máximo a uma cobertura secundária.

Do ponto de vista da análise quantitativa, o jornal que tem dedicado ao tema do Kosovo a maior atenção tem sido aquele de esquerda ou seja, Il Manifesto. $\mathrm{Da}$ análise mais detalhada de seus textos publicados durante a primeira semana do conflito, constata-se que eram dedicadas diariamente entre 10 e 13 páginas a textos e fotos referentes ao Kosovo. As primeiras páginas, ao invés, eram dedicadas às imagens e vinhetas acompanhadas frequentemente de expressões irônicas tais como: "Mas o Kosovo está longe" ou "NATO = morte". Em decorrência desta opção gráfica, de dedicar as primeiras páginas "ao aspecto visual", eram relativamente poucos os textos ali publicados (4 nos 7 números da primeira semana). As fotos e os desenhos foram os protagonistas na cobertura do conflito sobre as páginas do Il Manifesto, o qual publicava em média 50 imagens nos 7 números semanais. $\mathrm{O}$ destaque era dado principalmente aos fugitivos kosovares, às crianças de mãos dadas fugindo das bombas, às mulheres chorando a morte de seus maridos e filhos durante o conflito e aos idosos desesperados e forçados a abandonar suas casas. Diferentemente das fotos, a maior parte dos textos destacava sobretudo as questões referentes à guerra e à política (aproximadamente 110 artigos em 7 números semanais), antes que questões relacionadas aos refugiados e da ajuda humanitária (apenas 15 artigos na primeira semana). No transcurso da guerra, ou seja, durante 77 dias, Il Manifesto praticamente não alterou o modo de cobrila, dedicando ao conflito do Kosovo entre 11 e 13 páginas por número e publicando em média de 15 a 20 artigos diariamente. Durante cada semana eram escritos, portanto, entre 100 e 150 artigos, entre os quais somente de $10 \%$ a $15 \%$ diziam relação aos refugiados kosovares. A estatística completa das imagens deste conflito nas páginas do Il Manifesto atingem aproximadamente 950 páginas, com um total de 1400 a 1500 artigos, dos quais somente $15 \%$ sobre os kosovares. Como assinalado anteriormente, o percentual de textos nas primeiras páginas do Il Manifesto tem sido relativamente baixo, ao mesmo tempo eram exibidas grandes e significativas imagens, via de regra provocadoras e chocantes, tais como as dos bombardeamentos acidentais da Embaixada chinesa e do edíficio da televisão sérvia, ou ainda de escolas e hospitais destruídos pelas bombas. $\mathrm{O}$ número total de imagens e vinhetas nas páginas do Il Manifesto, ao longo dos 77 dias, foi de aproximadamente 520 , sendo que apenas entre $11 \%$ e $13 \%$ divulgadas na primeira página.

A principal característica do segundo jornal analisado, ou seja, Il Corriere della Sera, tem sido aquela do amplo tratamento do tema, sendo que a cada artigo em particular eram dedicadas numerosas colunas e, com frequência, também páginas inteiras. Seu posicionamento de centro e sua influência manifestaram-se não só no claro aprofundamento do tema por parte dos jornalistas, mas também no fato de que muitas reportagens e opiniões eram de autoria de políticos (seja italianos, seja europeus), filósofos, escritores e de várias 
outras personalidades. Em cada número apareciam cerca de 15 artigos (semelhante ao que ocorria com Il Manifesto), entre os quais a maior parte aparecia em primeiro plano (um significativo número de artigos também centralizados no alto nas primeiras páginas). Durante a primeira semana do conflito Il Corriere della Sera publicou por volta de 65 artigos referentes ao Kosovo e mais de 30 referiam-se aos fugitivos kosovares. A estatística final de tudo o que foi publicado durante o conflito prevaleceu igual a obtida na primeira semana, com significativas diferenças na última semana de abril e, esporadicamente em maio, quando as temáticas da ajuda humanitária, dos refugiados e dos civis passaram a ocupar até mais de 40 artigos semanalmente.

Em linhas gerais, porém, a tendência em manter sempre um número fixo de páginas e artigos referentes ao Kosovo não sofreu alterações e, portanto, a cada semana os textos dedicados a este tema não superavam os 100, ocupando o espaço de 7 a 8 páginas. Il Corriere della Sera, ao longo do conflito, num total de aproximadamente 600 páginas (número muito inferior àquele do Il Manifesto) publicou quase 1200 artigos, dos quais 230 (ou seja, cerca de $20 \%$ do total) referiamse à situação dos refugiados provenientes dos territórios em conflito.

La Stampa, o segundo dos jornais de centro e terceiro entre os examinados, foi aquele que, juntamente com IL Tempo tem dedicado à guerra do Kosovo o menor número de páginas, isto é de 6 a 7 páginas a cada número. A cada semana eram publicados cerca de 100 artigos (na maioria das vezes breves em relação aos demais jornais analisados), entre os quais praticamente $25 \%$ referiam-se aos kosovares. As ilustrações referentes ao Kosovo publicadas por La Stampa, não tem alcançado o destaque e a importância obtidos por Il Manifesto como também por La Repubblica: de fato o jornal em questão estampava um número relativamente baixo de fotos, por volta de 40 sobre 7 números semanais. A maior parte das imagens referiam-se, ao invés, aos políticos dos países envolvidos no conflito, às cenas de destruição das cidades bombardeadas e a outros aspectos da guerra.
Em 77 números de La Stampa, editados durante o transcorrer da guerra no Kosovo, o tema em questão ocupou mais de 500 páginas num total de aproximadamente 1100 artigos a respeito. O que tem distinguido decisivamente o jornal turinense dos demais tem sido o seu maior interesse para com as questões relacionadas às ações das agências humanitárias e da ajuda que prestam aos fugitivos da guerra; como também a atenção dada aos refugiados já estabelecidos na Itália e às suas perspectivas futuras (cerca de 300 , sobre 1100 artigos publicados em La Stampa, versavam sobre os kosovares). A questão dos civis que fugiam dos territórios em conflito, tem encontrado a sua relevância particular também nos serviços fotográficos: sobre cerca de 500 imagens publicadas ao longo da guerra, mais de 100 referiam-se aos refugiados kosovares.

La Repubblica, o último entre os jornais de centro (também se considerado mais de centro-esquerda), tem privilegiado o aspecto visual do conflito, publicando em cada número por volta de 15 (e às vezes mais de 20) imagens sobre o Kosovo. Dedicando diariamente entre 12 e 15 artigos num total de 8 ou 9 páginas (o equivalente aproximado a 700 páginas ao longo de todo o conflito), a exemplo do II Corriere della Sera, publicava numerosas entrevistas, correspondências, comentários e opiniões de políticos e personalidades públicas. Da mesma forma que Il Corriere, muitos dos textos apareciam em primeiro plano, centralizados na primeira página, atraindo a atenção dos leitores.

Levantamento realizado semanalmente apontava em média entre 100 e 110 artigos extensos (entre os quais de 12 a 15 na primeira página), acompanhados de uma centena de fotos, habitualmente com uma na primeira página. Um significativo acréscimo de artigos e imagens tem sido verificado nos últimos dias do conflito, quando eram publicadas até 30 imagens e os artigos superavam a casa dos 23 , aumentando também o número de páginas dedicadas à temática do Kosovo, de 8 ou 9 para 11. Uma outra mudança significativa, neste caso referente ao conteúdo dos textos, emergiu em meados de abril, na sequência das informações relativas à limpeza étnica, apareceram mais matérias sobre os refugiados e a população civil (antes, em geral, predominavam os temas políticos e da guerra, em detrimento daqueles de caráter civil). Os artigos faziam-se acompanhar de fotos de crianças, mulheres e idosos, por tratar-se dos mais vulneráveis no seio da sociedade.

No transcorrer do conflito, sobre aproximadamente 700 páginas, foram publicados quase 1200 artigos, à semelhança do verificado com Il Corriere della Sera, dos quais entre $13 \%$ e $14 \%$ na primeira página. Mais de 1000 imagens relacionadas ao conflito foram publicadas nas páginas de La Repubblica (por volta de 100 na primeira página), o que inegavelmente diferenciou este jornal dos demais.

Por fim, Il Tempo, último periódico analisado, também tem mantido uma postura uniforme ao tratar do conflito em curso: o tema mantinha-se presente mas não de modo exageradamente exposto, com destaque para o aspecto estratégico e político da guerra antes que daquele humanitário. Durante a primeira semana dos bombardeios, Il Tempo dedicava ao tema até 6 ou 7 páginas, o equivalente a mais ou menos 80 artigos, dos quais, em média, 2 apareciam diariamente na primeira página. Como já foi dito, os percentuais referentes às informações e às imagens sobre os refugiados (entrevistas com os fugitivos da guerra, opiniões dos agentes e voluntários das ONGs que atuavam em campo, reportagens e estatísticas) eram os mais baixos de todos os jornais analisados, cerca de $7 \%$ a $8 \%$ em relação ao total dos artigos e $8 \%$ ou $9 \%$ no tocante às imagens.

Os artigos publicados no Il Tempo eram de praxe extensos e tratavam da guerra em si, mas não faltavam tampouco as discussões políticas, entrevistas com as autoridades, comentários dos estrategistas, análises dos políticos e sondagens envolvendo os leitores. O que de fato chamou a atenção foi o relativamente baixo número de imagens. Durante toda a duração do conflito, nas cerca de 500 páginas dedicadas por Il Tempo ao Kosovo (muito próximo do jornal La Stampa), foram publicados mais de 900 artigos (em média entre 10 e 12 por dia), dos quais 
praticamente $15 \%$ nas primeiras páginas.

\section{A IMAGEM CRIADA:}

\section{ANÁLISE QUALITATIVA DO CONTEÚDO}

No estudo da imagem criada dos kosovares pelos 5 jornais pesquisados, não me deterei em analisar cada periódico em particular, mas procurarei traçar um quadro geral englobando a todos, visto que, embora existindo por vezes entre os mesmos uma carga emotiva diferente ao descrever os refugiados, a "imagem" criada tem sido muito semelhante em todos os casos. E até mesmo simples, de tendência contrastante: "pobrezinhos" e vitímas da guerra na fase inicial do conflito e "perigosos" ao final do mesmo.

Inicialmente, falava-se dos kosovares com muita compaixão, com piedade, narrando a sua sorte de modo tal a comover os italianos por esta situação dramática. Falava-se, portanto,"da realidade chocante", "da situação dramática", "do êxodo", "do terror e dos extermínios", "da catástrofe humana", "do drama dos refugiados", "da massa dos fugitivos de guerra", "das ondas que fogem em direção à fronteira", "das dimensões biblícas desta tragédia" e "de 250 mil em fuga, que deixaram seus lugarejos e se endereçam para as costas italianas". Para fazer com que a sociedade italiana se sentisse ainda mais envolvida, procurava-se fazer refletir a realidade kosovara na situação interna da Itália, utilizando-se de títulos alarmantes: "O governo italiano enfrentará a catástrofe humanitária" e " $\mathrm{Na}$ fronteira preparam-se para o pior".

Os fugitivos eram tratados com certa "delicadeza" no tom, mesmo usando palavras fortes, tais como: "os refugiados sem futuro", "os pobres sem-teto", "perdidos no mundo", "aos milhares em fuga", "desesperados", "expulsos" e "vítimas inocentes". Deste "pesadelo"que eram os refugiados, informava-se com maior ou menor "emotividade", de acordo com a tendência de cada jornal. La Stampa, por exemplo, utilizava com frequência muitos adjetivos e palavras elaboradas, concentrando-se na descrição detalhada das situações: "o sofrimento das pessoas... famílias divididas, uma mais que as outras: o homem jovem com o rosto queimado, a mulher com duas crianças ao colo, uma terceira criança - uma menininha seguindo-a com a cabeça baixa..." E em seguida, na página seguinte: As pessoas andam sem saber para onde ir, esfaimadas, não obstante o frio e a neve avançam lentamente em busca de um refúgio, aterrorizadas, aniquiladas, sós - forçadas a fugir." (La Stampa, 21 de março de 1999).

As descrições carregadas de emoção, na fase correspondente às primeiras semanas do conflito, eram a tônica entre os jornais analisados, portanto, também no Il Corriere della Sera, que informava: "entre os grupos dos fugitivos kosovares constatam-se ou últimos sinais de vida; as mulheres que tiveram que deixar seus maridos no Kosovo, choram, percebe-se todo o desespero no rosto dos idosos..."

A tendência geral de narrar as histórias das vítimas foi seguida também por $I l$ Manifesto, o qual, porém, diferentemente dos outros jornais, agregava a estas histórias acusações contra o governo italiano e a comunidade internacional. "Chegaram em número de 174. Coitados, sem uma mala, sem uma sacola, só lhes restou a roupa do corpo... 174 desesperados. Multidões de refugiados pelas estradas, abandonados à própria sorte, sem nenhum tipo de ajuda. As organizações humanitárias das Nações Unidas já fizeram suas malas..."

Esta imagem "da caridade", "do abismo dos desesperados", "do êxodo bíblico", "do êxodo em massa" e de "milhares e milhares de mulheres, crianças e idosos pelas estradas, caminhando em direção a Albânia", transmutou-se, no transcorrer da guerra, em uma outra: aquela "do perigo dos refugiados", "das intermináveis fugas", "das imagens virtuais" $e$ "das ondas de imigrantes ilegais que fugiam do Kosovo para alcançar a Itália e ali espalhar-se por todo o território."

De acordo com o que escreveu $I l$ Tempo, no dia 10 de junho de 1999 , portanto no último dia do conflito: "serão necessários pelo menos 20 anos para fazer retornar a todos os kosovares".
Entretanto, no que diz respeito às manchetes, as mais frequentes eram as que visavam atrair a atenção dos leitores, tais como: "Kosovo - gueto para os $600 \mathrm{mil}$ albaneses", "Continua o alarme na Puglia: chegam novos refugiados", "Mulheres e crianças no trem da morte", "A maior tragédia humana dos tempos do genocídio na Bósnia", "Dramático êxodo dos fugitivos", "Nova fronteira da desolação", "Massacres e execuções em massa", "Três mil abandonados: dormem ao relento e alimentam-se de plantas".

\section{ALGUMAS OBSERVAÇÕES FINAIS}

Conforme analisado neste estudo, o "peso" dos cinco jornais italianos, $I l$ Manifesto, La Repubblica, La Stampa, Il Corriere della Sera e Il Tempo, em influenciar a opinião pública, tanto no que se refere ao conflito no Kosovo, quanto às imagens dos refugiados kosovares, não deixa nenhuma dúvida.

Isso foi também confirmado por um levantamento acerca dos conflitos esquecidos, realizado pela Cáritas italiana em parceria com pesquisadores das universidades e de centros de pesquisa, no qual foi constatado que $60 \%$ dos italianos buscam informar-se sobre questões políticas, relações internacionais e assuntos de guerra através da televisão e do rádio, enquanto $28 \%$ declararam fazê-lo através da impensa escrita, seja ela diária, semanal ou mensal (Boccegato, 2003:52).

E a informação sobre o conflito no Kosovo, com certeza, não esteve ausente em nenhum dos meios de comunicação citados. De um ponto de vista científico, a visibilidade da guerra no Kosovo não surpreende, visto que corresponde perfeitamente à teoria da divisão do mundo entre Norte e Sul e à teoria mediática da regionalização dos conflitos. Segundo a teoria em questão, o interesse dos meios de comunicação predomina para os eventos e conflitos que acontecem nas regiões mais ricas e de maior relevância sob o ponto de vista estratégico, ou seja, aquelas do Norte, enquanto se nota uma tendência em omitir o que acontece no continente africano e na América do Sul. 
Para o que se passa na Europa, como por exemplo o conflito no Kosovo (muito importante do ponto de vista geopolítico), ou nos territórios dos países produtores de petróleo do Oriente Médio, sempre terão uma maior visibilidade em relação ao que acontece no hemisfério Sul do planeta. Efetivamente, os dados publicados na pesquisa da Cáritas confirmam que apenas $0,5 \%$ das pessoas entrevistadas sabiam da existência da guerra no Gongo, $1 \%$ dos conflitos no Burundi e em Angola e 2\% do conflito na Etiópia (Beccegato, 2003:48).

Os autores da pesquisa referida afirmam, porém, que o fator geográfico não é a única variável que pesa na decisão dos meios de comunicação. Também ganha relevância a proporção do conflito e sua repercussão em nível internacional (com o envolvimento no conflito por parte dos meios de comunicação internacionais da União Européia, da NATO, da ONU), bem como as relações históricas, econômicas e culturais entre o país em guerra e aquele no qual a mesma está sendo noticiada.

Ganha peso também a duração do conflito: aqueles de curta duração atraem a máxima atenção dos meios de comunicação praticamente do ínicio ao fim (como foi o caso da guerra no Kosovo); contrariamente, aqueles que duram anos, mais facilmente são substituídos por outros acontecimentos e, consequentemente, no transcorrer do tempo são simplesmente esquecidos (Beccegato, 2003:39).

Por essa razão, dada a sua importância, o conflito no Kosovo, que envolveu as estruturas políticas mundiais e européias, além de ter tido uma duração relativamente curta, alcançou enorme visibilidade seja por parte dos meios de comunicação internacionais que italianos. Não obstante tudo isso, porém, também neste caso, ao longo do conflito, notou-se uma ligeira queda na atenção e um certo cansaço com relação ao tema. Os kosovares, vistos na fase inicial da guerra como vítimas inocentes da política internacional, ao final da mesma começavam a ser apresentados como potencial "perigo" para os ricos países vizinhos da União Européia, enquanto refugiados à procura de uma solução permanente fora de seu país de origem.
Como afirma Ryszard Kapuscinski, em determinado momento "a informação verdadeira e propriamente dita passa para um segundo plano e o que de fato conta é o modo atraente de transmitir a notícia. A verdade deixa de ser relevante e sequer o é a luta política, a importância passa a ser o valor econômico do produto que pode ser vendido" (Roidi, 2001:96). E isso tem sido evidenciado no comportamento dos meios de comunicação italianos no caso do Kosovo e dos kosovares.

* Kamila Kowalska é jornalista, formada em Relações Internacionais, Imigração e Refugiados.

\section{REFERÊNCIAS BIBLIOGRÁFICAS}

ADAMOWSKI, J.; GOLKA, B.; STASIAKJAZUKIEWICZ, E.

(1997) Wybrane zagraniczne systemy informacji masowej cz. II, Elipsa Warszawa.

ARUFFO, A.

(1999) L'Inferno dei Balcani. Datanews, Roma.

BECCEGATO, P., NANNI, W. (red.)

(2003) I conflitti dimenticati, Caritas Italiana, Mediolan.

BETTETINI, G.

(1984) La conversazione audiovisiva, Bompiani, Milano.

\section{CARITAS}

(2002) Caritas e Migrantes, XII Rapporto sull'immigrazione. Dossier Statistico 2002, Roma.

CARITA

(2003) Caritas e Migrantes, XIII Rapporto sull'immigrazione. Dossier Statistico 2003, Roma.

\section{CARITAS}

(2004) Caritas e Migrantes, XIV Rapporto sull'immigrazione. Dossier Statistico 2004, Roma.

CHELI, E.

(1992) La realtà mediata. L'influenza dei mass media tra persuasione e costruzione sociale della realtà, Franco Angeli, Milano.

DOBEK-OSTROWSKA, B.

(1999) Podstawy komunikowania spolecznego, Astrum, Wroclaw.

GOBAN-KLAS, T.

(1999) Media i komunikowanie masowe. Teorie i analizy prasy, radia, telewizji i internetu, PWN, Warszawa-Kraków.
IGNATIEFF, M.

(2000) Virtual War: Kosovo and Beyond, Chatto Bodley Head and Cape,London.

KARWAT, M.

(2000) Sztuka manipulacji politycznej, Toruñ.

KRIPPENDORF, $\mathrm{K}$.

(s/d) Analisi del contenuto. Introduzione metodologica.

LUKOVIFE, M.

(2000) Kryzys kosowski oczyma Serbów, Belgrad.

MACIOTI, M.!., PUGLIESE, E.

(2003) L'esperienza migratoria. Immigrati e rifugiati in Italia, Editori Laterza, Roma.

MENDUNI, E.

(1996) La piu' amata dagli Italiani, Bologna.

MURIALDI, P.

(1998) La stampa italiana dalla Liberazione alla crisi di fine secolo, Editori Laterza.

MAGDZIAK-MISZEWSKA, A. (red.)

(2000) Swiat po Kosowie, Warszawa.

NAVA, M.

(1999) Kosovo c'ero anch'io, Milano.

MOROZZO DELLA ROCCA, R.

(1999) Kosovo. La guerra in Europa, Milano.

NATO

(1999r) "Rivista della NATO", nr.2 estate. ROIDI, V.

(2001) La fabbrica delle notizie. Piccola guida ai quotidiani italiani, Laterza Bari.

RICCI, P. (red.)

(s/d) II linguaggio della stampa quotidiana, Giunti/Marzocco.

STATERA, G.

(1993) Società e comunicazioni di massa, Palumbo, Palermo.

(2000) The Media in Western Europe, Londyn.

THOMPSON, J. B.

(2001) Media i nowoczesnoœæ. Spoleczna teoria mediów, Astrum, Wroclaw.

TRUTKOWSKI, C.

(2000) Spoleczne reprezentacje polityki, Wydawnictwo naukowe "Scholar", Warszawa.

(2000) UNHCR, Uchodzcy Zwiata. 50 lat pomocy humanitarnej.

WOLF, M.

(1989) Teorie delle comunicazioni di massa, Bompiani, Milano.

WOLF, M.

(1992) Gli effetti sociali dei media, Bompiani, Milano. 